\title{
Caspase-independent cell death revealed in human gastric cancer cell lines, MKN45 and KATO III treated with phenoxazine derivatives
}

\author{
TERUHIKO KASUGA ${ }^{1}$, TAKAFUMI TABUCHI ${ }^{1}$, KEN SHIRATO $^{2}$, KAZUHIKO IMAIZUMI $^{2}$ and AKIO TOMODA $^{3}$ \\ ${ }^{1}$ Fourth Department of Surgery, Tokyo Medical University, Kasumigaura Hospital, 3-20-1 Chuo, Ami, Inashiki, \\ Ibaraki 300-0395; ${ }^{2}$ Laboratory of Physiological Sciences, Faculty of Human Sciences, Waseda University, \\ 2-579-15 Mikajima, Tokorozawa, Saitama 359-1192; ${ }^{3}$ Department of Biochemistry, \\ Tokyo Medical University, 6-1-1 Shinjuku, Tokyo 160-8404, Japan
}

Received September 18, 2006; Accepted November 20, 2006

\begin{abstract}
We examined whether phenoxazine derivatives such as 2-amino-4,4 $\alpha$-dihydro-4 $\alpha, 7$-dimethyl-3H-phenoxazine3-one (Phx-1) and 2-aminophenoxazine-3-one (Phx-3) may have anticancer effects on the human gastric cancer cell lines, MKN45, MKN74, MKN7 and KATO III in vitro. Phx-1 inhibited the growth of these cancer cells in a dose- and timedependent manner. The $\mathrm{IC}_{50}$ was approximately 65, 25, 100 and $70 \mu \mathrm{M}$ for MKN45, MKN74, MKN7 and KATO III respectively, after $72 \mathrm{~h}$. Phx-3 exerted stronger antiproliferative effects against these cancer cells $\left(\mathrm{IC}_{50}\right.$ : approximately 5, 1, 10 and $10 \mu \mathrm{M}$ for MKN45, MKN74, MKN7 and KATO III, respectively, after $72 \mathrm{~h}$ ) than Phx-1. Phx-1 and Phx-3 increased the population of TUNEL-positive cells in MKN45 and KATO III time-dependently from 24 to $72 \mathrm{~h}$, suggesting that $\mathrm{Phx}-1$ and Phx-3 have apoptotic activity against these gastric cancer cells. The activity of effector caspase- 3 significantly increased in MKN45 treated with Phx-3 for $24 \mathrm{~h}$, but did not altered in the cells treated with Phx-1 for $24 \mathrm{~h}$. When $\mathrm{z}$-VAD-fmk, a pan-caspase inhibitor, was co-treated for $24 \mathrm{~h}$, Phx-3-stimulated caspase-3 activity in MKN45 was reversed to the levels of normal activity, while the antiproliferative and apoptotic effects of Phx-3 against the cells were maintained. The activity of caspase- 3 was not activated in KATO III by $24 \mathrm{~h}$ exposure for $\mathrm{Phx}-1$ or $\mathrm{Phx}-3$. In conclusion, both phenoxazines prevent the growth of the human gastric cancer cell lines, MKN45 and KATO III in vitro, and cause the apoptosis of these cell lines via a caspase-independent
\end{abstract}

Correspondence to: Dr Akio Tomoda, Department of Biochemistry and Research Institute of Immunological Treatment, Tokyo Medical University, 6-1-1 Shinjuku, Tokyo 160-8404, Japan E-mail: tomoda@tokyo-med.ac.jp

Key words: phenoxazines, gastric cancer cells, caspase-independent apoptosis, cell cycle arrest pathway. Although the intracellular action mechanisms of Phx-1 and Phx-3 are still unclear, these phenoxazines may be useful for the treatment of gastric cancer in the future.

\section{Introduction}

Gastric cancer, a malignant tumor arising from the region between esophagogastric junction and the pylorus, is common worldwide, and is difficult to cure by chemotherapy alone $(1,2)$. Anticancer drugs such as 5-fluorouracil and cisplatin used for its treatment could induce severe adverse effects $(3,4)$. We therefore need anticancer drugs, inducing apoptosis of cancer cells at low doses, to minimize adverse effects (5-7).

Since the discovery of Actinomycin D, which includes phenoxazine in its chemical structure and exerts strong anticancer activity $(8,9)$, phenoxazine compounds have been studied as possible anticancer drugs. However, the chemically synthesized phenoxazines showed little anticancer activity $(10,11)$, probably because of lower solubility in water. Recently, it has been reported that phenoxazine derivatives, 2-amino-4,4 $\alpha$-dihydro-4 $\alpha, 7$-dimethyl-3H-phenoxazine-3-one (Phx-1) and 2-aminophenoxazine-3-one (Phx-3), which were produced by the reaction of o-aminophenol and its derivative with bovine hemoglobin $(12,13)$ and are relatively soluble in water, exert anticancer effects on a variety of carcinoma cells (14-18) both in vitro and in vivo. In particular, these phenoxazines were found to show little adverse effects on mice $(14,19,20)$. However, the anticancer effects of Phx-1 and Phx-3 on the human gastric cancer cell lines, extremely refractory to chemotherapeutic reagents $(1,2)$, have not been examined. In addition, though it was shown that Phx-1 and Phx- 3 cause apoptosis of some carcinoma cell lines (14-18), the detailed pathways for apoptosis caused by Phx-1 and Phx-3 have not been sufficiently investigated in these cases.

In the present study, we investigated the anticancer effects of Phx-1 and Phx-3 on the human gastric cancer cell lines, MKN45 and KATO III, focusing on caspase-dependent or caspase-independent apoptotic cell death in gastric cancer cell lines. 
(A)<smiles>Cc1ccc2c(c1)OC1(C)CC(=O)C(N)=CC1=N2</smiles>

(B)

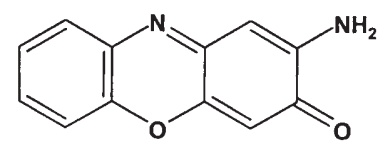

Figure 1. Chemical structure of the phenoxazine derivatives used in the present study. (A) 2-amino-4,4 $\alpha$-dihydro-4 $\alpha, 7$-dimethyl-3H-phenoxazine-3one (Phx-1) and (B) 2-aminophenoxazine-3-one (Phx-3).

\section{Materials and methods}

Phenoxazine derivatives. Phenoxazines, 2-amino-4,4 $\alpha$-dihydro4a,7-dimethyl-3H-phenoxazine-3-one (Phx-1) and 2-aminophenoxazine-3-one (Phx-3) were prepared according to the methods described by Tomoda et al (12) and Shimizu et al (13). The chemical structure of these compounds is illustrated in Fig. 1. Phx-1 and Phx-3 were dissolved in a mixture of dimethylsulfoxide (DMSO) and ethyl alcohol (EtOH) (3:1) to make $20 \mathrm{mM}$ solutions, which were added to the culture medium to reach final concentrations of $1.25-100 \mu \mathrm{M}$.

Cell lines and culture condition. The human gastric cancer cell lines, MKN45, MKN74, MKN7, KATO III, were obtained from the Health Science Research Resources Bank (HSRRB, Osaka, Japan). MKN45, MKN74 and MKN7 and KATO III were poorly-differentiated adenocarcinoma, moderatelydifferentiated tubular adenocarcinoma, well-differentiated tubular adenocarcinoma and signet ring cell carcinoma, respectively. These cells were cultured in Eagle's minimum essential medium $\alpha(\mathrm{MEM} \alpha)$ (Kohjin Bio, Saitama, Japan) supplemented with $80 \mathrm{mg} / \mathrm{l}$ kanamycin sulfate (Wako Pure Chemicals, Tokyo, Japan) and 10\% heat inactivated fetal bovine serum (FBS) (Sigma, St. Louis, MO, USA) in a humidified incubator containing $5 \% \mathrm{CO}_{2} / 95 \%$ air at $37^{\circ} \mathrm{C}$.

Cell viability assay. The viability of cells was assessed fluorometrically using the CellTiter-Blue ${ }^{\mathrm{TM}}$ Cell Viability Assay (Promega, Madison, WI, USA). Adherent cells such as MKN45 (1x10 cells/ml), MKN74 (1x10 cells/ml) and MKN7 $\left(5 \times 10^{4}\right.$ cells $\left./ \mathrm{ml}\right)$ were pre-cultured in 48 -well flat-bottomed microtiter plates for $24 \mathrm{~h}$, and then treated with fresh culture medium containing various concentrations of Phx-1 (0-100 $\mu \mathrm{M})$ or Phx-3 $(0-20 \mu \mathrm{M})$. Non-adherent cells such as KATO III $\left(1 \times 10^{5}\right.$ cells $\left./ \mathrm{ml}\right)$ were treated with various concentrations of Phx-1 (0-100 $\mu \mathrm{M})$ or Phx-3 $(0-40 \mu \mathrm{M})$ in 6-well flatbottomed microtiter plates. After 24,48 and $72 \mathrm{~h}$ of treatment, MKN45, MKN74 and MKN7 were treated with fresh culture medium, and then the CellTiter-Blue ${ }^{\mathrm{TM}}$ reagent (Resazurin, 7-hydroxy-3H-phenoxazin-3-one 10-oxide) was added in each well, while KATO III was collected by centrifugation, resuspended in fresh culture medium, and dispensed in 48-well flat-bottomed microtiter plate. The incubation was continued for $1 \mathrm{~h}$, resorufin (7-hydroxy-3H-phenoxazin-3one), reduced form of resazurin, was analyzed using a multi- detection microplate reader (Model Powerscan HT, Dainippon Pharmaceutical, Osaka, Japan) at a wavelength of $560 \mathrm{~nm}$ excitation/590 nm emission. The viability of cells was determined by referring to the fluorescence of cells treated without Phx-1 or Phx-3.

Apoptosis detection. The detection of apoptosis was performed flow cytometrically using the ApoDirect In Situ DNA Fragmentation Assay Kit [Medical and Biological Laboratories (MBL), Nagoya, Japan], which was based on the terminal deoxynucleotidyl transferase (TdT)-mediated deoxyuridine triphosphate (dUTP)-biotin nick end labeling (TUNEL) assay. MKN45 and KATO III $\left(1 \times 10^{5}\right.$ cells $\left./ \mathrm{ml}\right)$ were treated with the indicated concentrations of Phx-1 or Phx-3, or vehicle for 24,48 and $72 \mathrm{~h}$ in $25 \mathrm{~cm}^{2}$ cell culture flask. The cells were collected, fixed by $1 \%$ (weight/volume) paraformaldehyde in PBS (pH 7.4), and placed on ice for 15 min. After washing twice with PBS (pH 7.4), the cells were fixed by $70 \%$ (volume/volume) $\mathrm{EtOH}$, and placed on ice for $30 \mathrm{~min}$. The cells were twice washed with $1 \mathrm{ml}$ of the wash buffer, and stained with $50 \mu \mathrm{l}$ of the staining solution containing TdT reaction buffer $(10 \mu 1)$, TdT enzyme $(0.75 \mu 1)$, FITC-dUTP $(8 \mu 1)$ and ultrapure water $(32.25 \mu 1)$, which were incubated at $37^{\circ} \mathrm{C}$ for $1 \mathrm{~h}$. Then, the cells were twice rinsed with $1 \mathrm{ml}$ of the rinse buffer, and stained with $500 \mu 1$ of the propidium iodide/RNase A solution, then incubated at room temperature for $30 \mathrm{~min}$ in the dark. These samples were analyzed with a flow cytometer (Partec PAS, Partec). FITC and PI staining were monitored using an FITC signal detector (FL1, $520 \mathrm{~nm}$ ) and phycoerythrin emission signal detector (FL3, 590-650 $\mathrm{nm})$, respectively.

Measurement of caspase-3 in MKN45 and KATO III. The activity of caspase-3 was measured fluorometrically using the DEVD-AFC, LEHD-AFC and IETD-AFC (MBL), respectively. MKN45 and KATO III $\left(1 \times 10^{5}\right.$ cells $\left./ \mathrm{ml}\right)$ were treated with the indicated concentrations of Phx-1 or Phx-3, or vehicle for $6-72 \mathrm{~h}$ in a $75 \mathrm{~cm}^{2}$ cell culture flask. The cells were collected, washed once with PBS (pH 7.4) and treated with $200 \mu 1$ of the cell lysis buffer (MBL), which were incubated on ice for $10 \mathrm{~min}$. These lysates were diluted by adding $300 \mu \mathrm{l}$ of the dilution buffer (MBL), and then $50 \mu 1$ of the $2 \mathrm{X}$ reaction buffer (MBL) and $5 \mu 1$ of DEVD-AFC, LEHD-AFC or IETDAFC were added to $50 \mu \mathrm{l}$ aliquots, which were incubated at $37^{\circ} \mathrm{C}$ for $1 \mathrm{~h}$ in the dark. These samples were analyzed using a multi-detection microplate reader (Powerscan HT, Dainippon Pharmaceutical) at a wavelength of $400 \mathrm{~nm}$ excitation/505 nm emission. The activity of caspase-3/7 was triplicated, corrected by protein contents, and expressed as the relative ratio of the activity in cells treated with $\mathrm{Phx}-1$ or Phx-3 to that in control cells treated with vehicle at each time-point.

Examination of the effects of a caspase inhibitor on caspase-3 and apoptosis in MKN45 and KATO III. In the present study, a pan-caspase inhibitor, $N$-benzyloxy-carbonyl-Val-Ala-Aspfluoromethylketone (z-VAD-fmk) (MBL) was used. This chemical was dissolved in DMSO to make $20 \mathrm{mM}$ solution, and then this solution was added in culture medium to reach a final concentration of $50 \mu \mathrm{M}$ during experiments. MKN45 or KATO III was divided into four groups as follows: i) control 
cells treated with vehicle, ii) cells treated with the indicated concentrations of Phx-1 or Phx-3, iii) cells treated with z-VADfmk, and iv) cells treated with the indicated concentrations of Phx-1 or Phx-3 and z-VAD-fmk. The third and fourth group cells were pre-treated with $\mathrm{z}$-VAD-fmk for $1 \mathrm{~h}$, while the first and second group cells were pre-treated with the same quantity of DMSO for the same period. Then, the treatment of cells with Phx-1, Phx-3 or vehicle, and z-VAD-fmk or DMSO was performed for $24 \mathrm{~h}$. The activity of caspase- 3 and the viability of cells were examined, and the detection of apoptosis was performed as described above.

Cell cycle analysis. The analysis of cell cycle was performed flow cytometrically using the CyStain DNA 2 step (Partec, Münster, Germany). MKN45 and KATO III ( $1 \times 10^{5}$ cells/ml) were treated with the indicated concentrations of $\mathrm{Phx}-1$ or $\mathrm{Phx}-3$, or vehicle (DMSO/EtOH) for 24, 48 and $72 \mathrm{~h}$ in $25 \mathrm{~cm}^{2}$ cell culture flask. Then, the cells were collected, once washed with phosphate-buffered saline (PBS, $\mathrm{pH}$ 7.4) and treated with $1 \mathrm{ml}$ of the nuclei extraction buffer, which were incubated at room temperature for $10 \mathrm{~min}$. The extracted nuclei were stained with $5 \mathrm{ml}$ of the 4'-6-diamidino-2-phenylindole (DAPI) staining regent and incubated at room temperature for $10 \mathrm{~min}$ in the dark. These samples were analyzed with a flow cytometer using the cell cycle analysis program, MultiCycle AV (Phoenix Flow System, San Diego, CA, USA).

Statistical analysis. Experimental data are presented as means \pm SE. Unpaired Student's t-test was performed to examine the differences between each experimental group cells. A p-value $<0.5$ was considered to indicate a statistically significant difference.

\section{Results}

Antiproliferative effects of Phx-1 and Phx-3 on the human gastric cancer cell lines, MKN45, MKN74, MKN7 and KATO III. Antiproliferative effects of various concentrations of Phx-1 and Phx-3 on the growth of 4 characteristic human gastric cancer cell lines, MKN45, MKN74, MKN7 and KATO III were studied, 24, 48 and $72 \mathrm{~h}$ after treatment of these phenoxazines. Both Phx-1 and Phx-3 exhibited antiproliferative effects on MKN45, MKN74 and MKN7, timeand dose-dependently (Fig. 2A-C). The $\mathrm{IC}_{50}$ of Phx-1 was $\sim 65,25$ and $100 \mu \mathrm{M}$ for MKN45, MKN74 and MKN7 cells, respectively, after $72 \mathrm{~h}$. Phx-3 exerted stronger antiproliferative effects on these cancer cells $\left(\mathrm{IC}_{50}: \sim 5,1\right.$ and $10 \mu \mathrm{M}$ for MKN45, MKN74 and MKN7, respectively, after $72 \mathrm{~h}$ ).

Phx-1 moderately inhibited the growth of KATO III, timeand dose-dependently (Fig. 2D, left column). The $\mathrm{IC}_{50}$ of Phx-1 was $\sim 70 \mu \mathrm{M}$ for KATO III, after $72 \mathrm{~h}$. Phx-3 exerted stronger antiproliferative effects on KATO III $\left(\mathrm{IC}_{50}: \sim 10 \mu \mathrm{M}\right.$ after 72 h; Fig. 2D, right column). KATO III are non-adherent cells that originate from signet ring cell carcinoma, and MKN45, MKN74 and MKN7 are adherent to a culture plate. Furthermore, MKN45 and KATO III are undifferentiated cancer cells with higher malignancy. Thus, we investigated the apoptotic mechanism of MKN45 and KATO III caused by $\mathrm{Phx}-1$ and $\mathrm{Phx}-3$ in the following experiments.
(A)
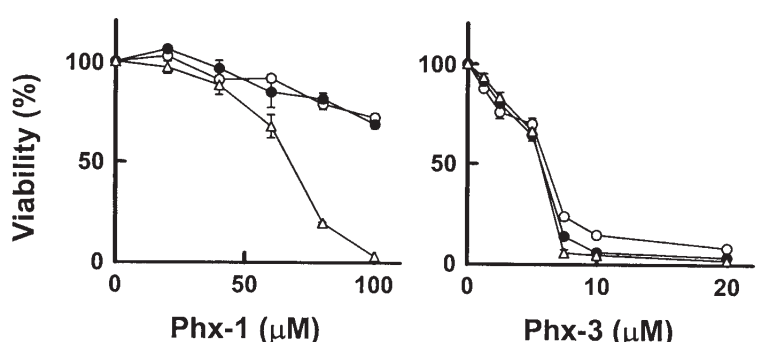

(B)
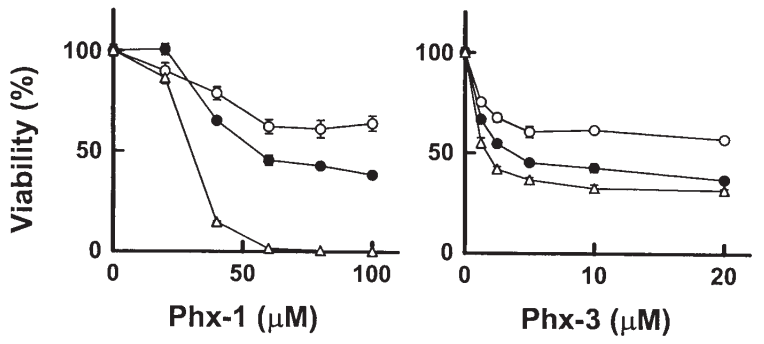

(C)
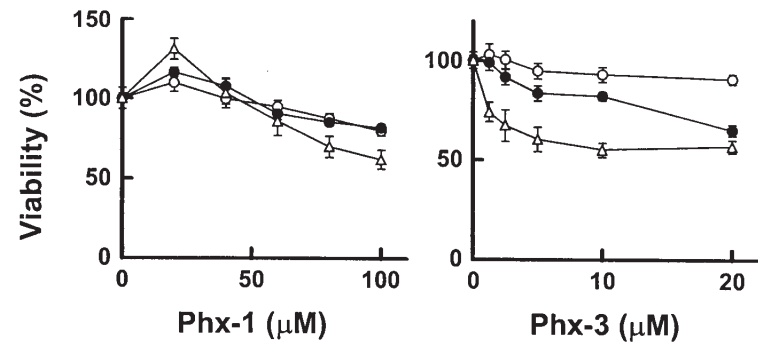

(D)
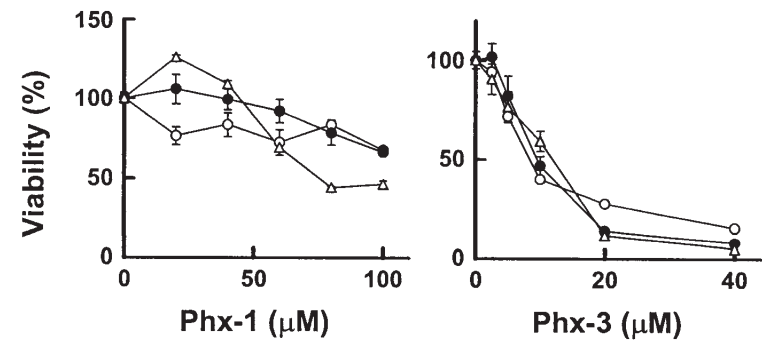

Figure 2. Effects of Phx-1 and Phx-3 on the growth of human gastric cancer cell lines, MKN45, MKN74, MKN7 and KATO III. MKN45 (A), MKN74 (B), MKN7 (C) and KATO III (D) were treated with various concentrations of Phx-1 (0-100 $\mu \mathrm{M})$ and Phx-3 (0-40 $\mu \mathrm{M})$ for $24 \mathrm{~h} \mathrm{(o),} 48 \mathrm{~h}(\bullet)$ and $72 \mathrm{~h}$ $(\Delta)$. Values, means \pm SE $(n=6)$.

Effects of Phx-1 and Phx-3 on apoptosis/necrosis in human gastric cancer cell lines, MKN45 and KATO III. We studied whether the prevention of cell growth of MKN45 and KATO III caused by Phx-1 and Phx- 3 was associated with induction of cell death such as apoptosis and necrosis. As shown in the left columns of Fig. 3A and B, the population of cells negative on both TUNEL and PI (viable cells, plots in the bottom left quadrant) was mostly observed in the control cells treated with vehicle in both MKN45 and KATO III during 24-72 h. When MKN45 were treated with $100 \mu \mathrm{M}$ Phx-1 or 7.5 $\mu \mathrm{M}$ Phx-3 for 24-72 h (Fig. 3A, middle and right columns, respectively), population of the viable cells was gradually decreased, and that of the early phase apoptotic cells and the late phase apoptotic/necrotic cells, expressed as TUNELpositive cells $(8.1,8.4$ and $63.4 \%$ after 24,48 and $72 \mathrm{~h}$ for Phx-1, respectively; 7.2, 22.1 and $39.6 \%$, after 24,48 and $72 \mathrm{~h}$ for Phx-3, respectively, bottom right quadrant in the figure) and both TUNEL- and PI-positive cells (5.2, 9.4 and 23.4\% 
(A)

\section{Control Phx-1 (+) Phx-3 (+)}
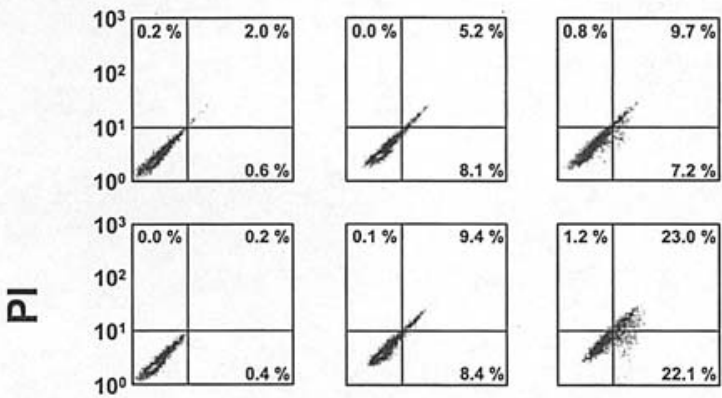

$24 \mathrm{~h}$
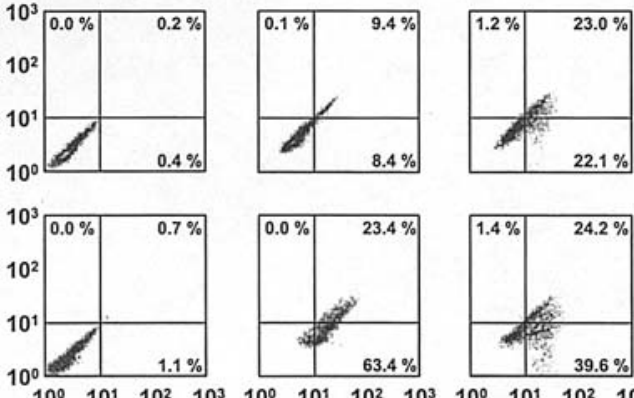

$48 \mathrm{~h}$

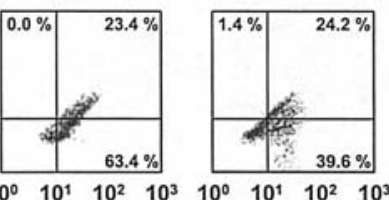

TUNEL
Phx-1

(A)

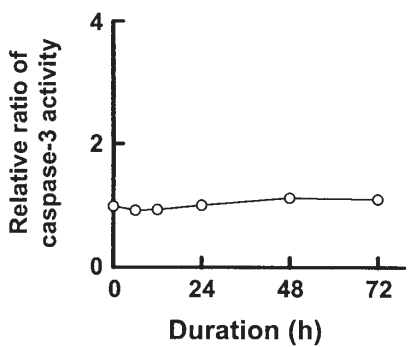

(B)

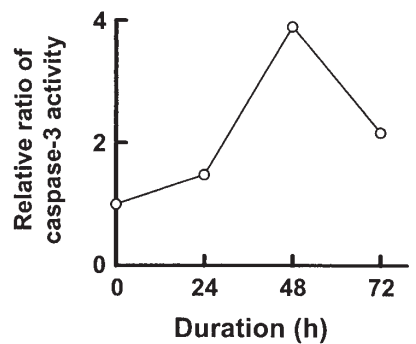

Phx-3
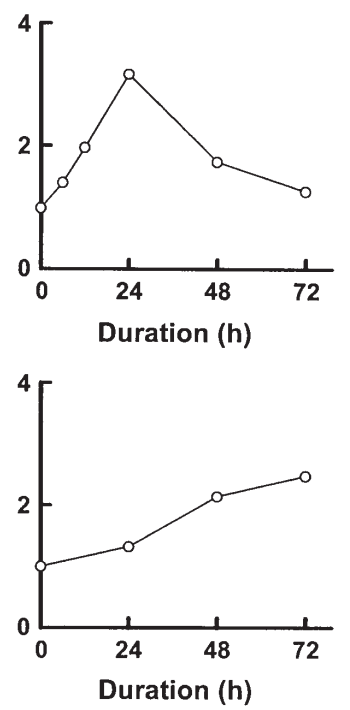

(B)

\section{Control}

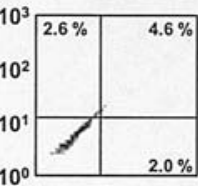

$\bar{\alpha}$
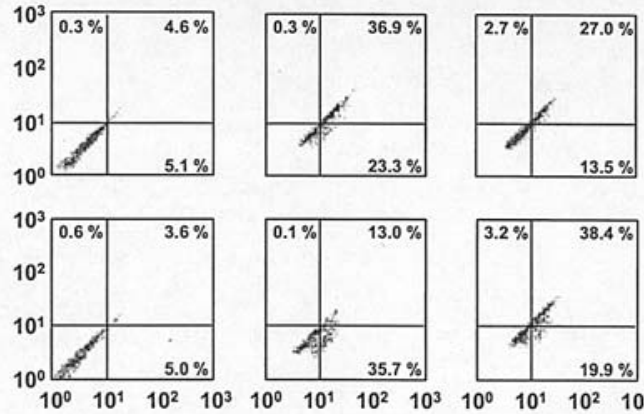

TUNEL
$24 \mathrm{~h}$

$48 \mathrm{~h}$

$72 \mathrm{~h}$

Figure 4. Changes in activity of caspase- 3 in human gastric cancer cell lines, MKN45 and KATO III treated with or without phenoxazines. MKN 45 (A) was treated with or without $100 \mu \mathrm{M} \mathrm{Phx}-1$ or $7.5 \mu \mathrm{M}$ Phx-3, while KATO III (B) was treated with or without $100 \mu \mathrm{M} \mathrm{Phx}-1$ or $20 \mu \mathrm{M} \mathrm{Phx}-3$, for $72 \mathrm{~h}$. The triplicate data are presented as the relative ratio of the activities of caspase-3 (o) in phenoxazine-treated cells to those in control cells.

Changes in capase-3 activity in human gastric cancer cell lines, MKN45 and KATO III treated with Phx-1 or Phx-3. The activity of caspase-3 was examined as a function of time (h) in MKN45 and KATO III treated with Phx-1 or Phx-3 for $0-72 \mathrm{~h}$, in order to elucidate the involvement of apoptotic signaling pathway in the apoptosis/necrosis of these cells (Fig. 4). Caspase-3 was not activated in MKN45 during $72 \mathrm{~h}$ exposure for $100 \mu \mathrm{M} \mathrm{Phx}-1$ (Fig. 4A, left column), while it was activated as much as 3.2 times by $24 \mathrm{~h}$ exposure for $7.5 \mu \mathrm{M}$ Phx-3 (Fig. 4A, right column). Caspase-3 was slightly activated after $24 \mathrm{~h}$, and markedly activated after $48 \mathrm{~h}(3.9$ times of the control) in KATO III treated with $100 \mu \mathrm{M}$ Phx-1 (Fig. 4B, left column), but it was slightly activated after $24 \mathrm{~h}$, and moderately activated after $48 \mathrm{~h}$ in the cells treated with $20 \mu \mathrm{M}$ Phx-3 (2.2-2.5 times of the control) (Fig. 4B, right column). Consequently, caspase-3 activity was significantly activated at 24 h only in MKN45 treated with Phx-3. Figure 3. Detection of apoptosis in human gastric cancer cell lines, MKN45
and KATO III treated with or without phenoxazines. MKN45 (A) was treated with or without $100 \mu \mathrm{M} \mathrm{Phx}-1$ or $7.5 \mu \mathrm{M} \mathrm{Phx}-3$, while KATO III (B) was treated with or without $100 \mu \mathrm{M} \mathrm{Phx}-1$ or $20 \mu \mathrm{M} \mathrm{Phx}-3$, for $24-72 \mathrm{~h}$. The apoptosis was detected flow-cytometrically by TUNEL assay. In each dot plot, the percentages of TUNEL (-) and PI (-) (viable cells, bottom-left quadrant), TUNEL (+) and PI (-) (cells in early stage apoptosis, bottom-right quadrant), TUNEL $(+)$ and PI $(+)$ (cells in late stage apoptosis/necrosis, topright quadrant), and TUNEL (-) and PI (+) (cells in necrosis, top-left quadrant) are described.

after 24, 48 and $72 \mathrm{~h}$ for Phx-1, respectively; 9.7, 23.0 and $24.2 \%$ after 24,48 and $72 \mathrm{~h}$ for $\mathrm{Phx}-3$, respectively. top right quadrant in the figure), respectively, increased in a timedependent manner. Similar effects were observed in KATO III treated with $100 \mu \mathrm{M}$ Phx-1 or $10 \mu \mathrm{M} \mathrm{Phx}-3$ (Fig. 3B). These results indicate that $\mathrm{Phx}-1$ and $\mathrm{Phx}-3$ are capable of inducing mixed type of cell death - apoptosis and necrosis in human gastric cancer cell lines, MKN45 and KATO III.

Involvement of caspase-independent pathway in the apoptogenesis in gastric cancer cell lines, MKN45 and KATO III. Caspase- 3 has been considered to be involved in the apoptogenesis in cancer cells treated with anticancer drugs $(21,22)$. On the other hand, Park et al (23) recently reported that caspase-independent pathway may be involved in the apoptogenesis in gastric cancer cells. We found that caspase-3 activity in MKN45 was significantly augmented by Phx-3 at $24 \mathrm{~h}$ (Fig. 4, right column). Therefore, we studied whether the apoptogenic effects of Phx-3 in MKN45 at 24 h may be dependent on the elevation of activity of caspase- 3 or not, by using the pan-caspase inhibitor, z-VAD-fmk. Phx-3-caused growth inhibition and apoptosis induction in MKN45 may be dependent on the activation of caspase- 3 , it is possible that 
(A)

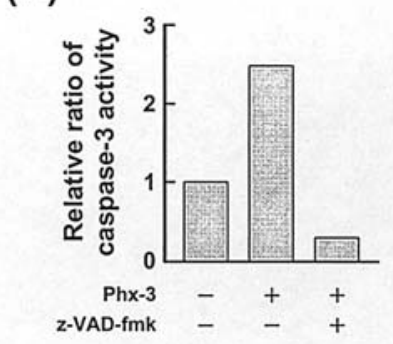

(B)

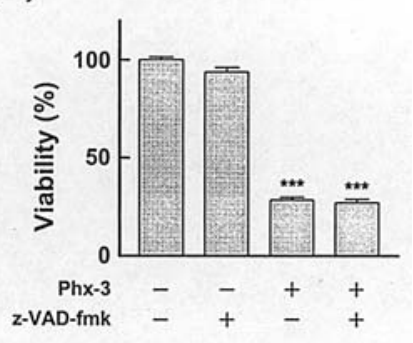

(C)

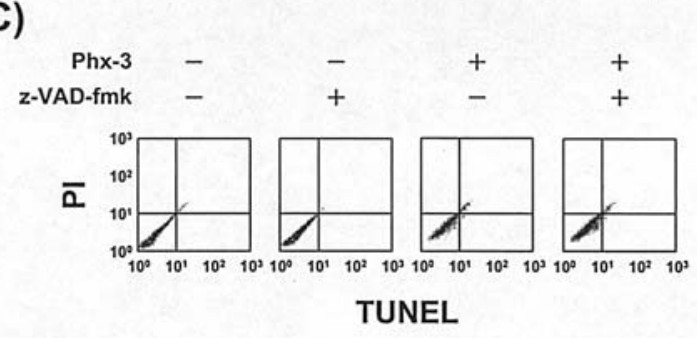

Figure 5. Effect of z-VAD-fmk on the activation of caspase-3, inhibition of growth and apoptosis of human gastric cancer cell lines, MKN45 induced by Phx-3. (A) Effect of z-VAD-fmk on Phx-3-induced activation of caspase-3 in MKN45; (B) Effect of z-VAD-fmk on Phx-3-inhibited growth in MKN45; and $(\mathrm{C})$ Effect of $\mathrm{z}$-VAD-fmk on Phx-3-induced apoptosis in MKN45 detected by FACscaning. ${ }^{* * *} \mathrm{p}<0.001$ (vs. control).

z-VAD-fmk cancels the inhibition of the growth, apoptosis induction of the cells and the augmented activity of caspase- 3 caused by $\mathrm{Phx}-3$.

As shown in Fig. 5A, caspase-3 activity was activated in MKN45 treated with $7.5 \mu \mathrm{M} \mathrm{Phx}-3$ alone at $24 \mathrm{~h}$, and it was completely cancelled by treatment with $50 \mu \mathrm{M}$ z-VAD-fmk in MKN45. However, Phx-3-caused inhibition of the viability of MKN45 was not reversed to normal levels by co-treatment with z-VAD-fmk (Fig. 5B).

When MKN45 was treated with z-VAD-fmk alone, the population of apoptosis/necrosis cells was not changed com-

pared with control cells (Fig. 5C). The population of apoptosis/ necrosis cells was significantly increased in MKN45 cells treated with $\mathrm{Phx}-3$, however, it was not reversed to the normal levels, when MKN45 was treated with both Phx-3 and z-VAD-fmk (Fig. 5C). These results (Fig. 5) suggest that the Phx-3-induced inhibition of cell viability and apoptosis/ necrosis in MKN45 were not associated with the activation of caspase- 3 .

Effects of Phx-1 and Phx-3 on cell cycle arrest in MKN45 and KATO III. We studied the effects of Phx-1 and Phx-3 on cell cycle arrest in MKN45 and KATO III. As shown in Fig. 6A, Phx-1 caused $\mathrm{G}_{0} / \mathrm{G}_{1}$ phase arrest in MKN45, while Phx-3 induced arrest at the S-phase. However, neither Phx-1 nor Phx-3 caused cell cycle arrest in KATO III (Fig. 6B).

\section{Discussion}

We investigated whether Phx-1 and Phx-3, which are relatively water-soluble compared with other chemically synthesizedphenoxazines, may prevent cellular growth and cause induction of caspase-dependent or independent apoptosis in gastric cancer cells. We used the human gastric cancer cell lines MKN45, MKN74, MKN7 cells and KATO III. The growth of these cells was significantly inhibited by $\mathrm{Phx}-1$ or $\mathrm{Phx}-3$ in a dose- and time-dependent manner (Fig. 2). The $\mathrm{IC}_{50}$ of Phx-1 and Phx-3 in these cells ranged from 1 to $100 \mu \mathrm{M}$, and these values were comparable to $\mathrm{IC}_{50}$ of these phenoxazines in various cancer cells (14-19), and to those of 5-fluorouracil in human gastric cancer cells (3), suggesting that Phx-1 and Phx-3 may be cytotoxic to gastric cancer cells. MKN45 is relatively sensitive to chemothera-peutic agents such as 5-fluorouracil (3) and troglitazone (24), while KATO III has been demonstrated to be extremely refractory to these agents. In this context, the behavior of Phx-1 and Phx-3 was different, because these phenoxazines caused growth inhibition of each of the gastric cancer cell lines, MKN45, MKN74, MKN7 and KATO III.

(A)

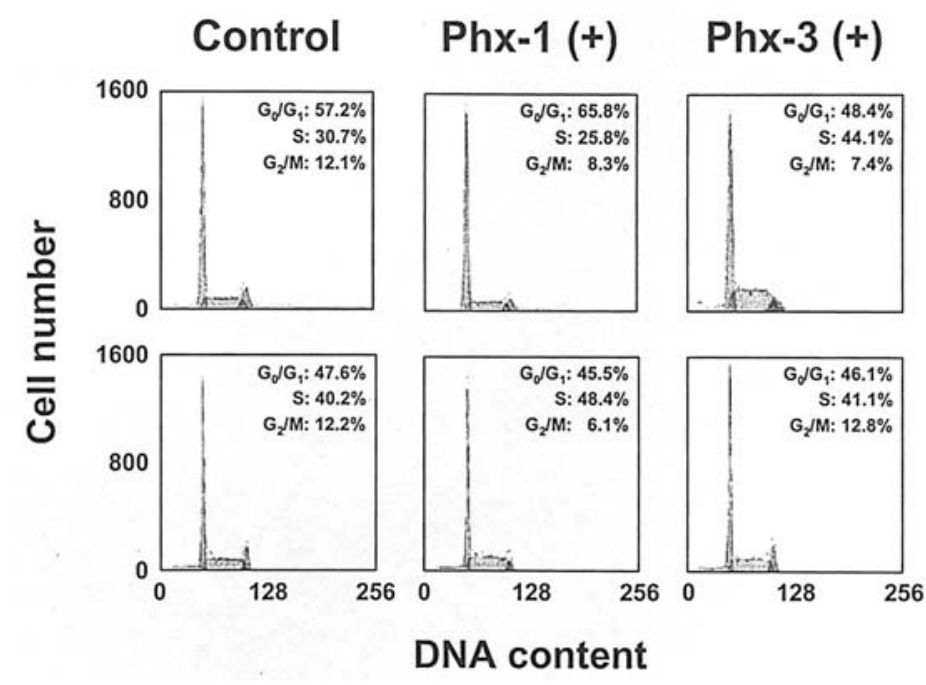

Figure 6. Flow cytometric analysis of cell cycle in human gastric cancer cell lines, MKN45 and KATO III treated with or without phenoxazines. MKN 45 (A) was treated with or without $100 \mu \mathrm{M}$ Phx-1 or $7.5 \mu \mathrm{M}$ Phx-3, while KATO III (B) was treated with or without $100 \mu \mathrm{M}$ Phx-1 or $20 \mu \mathrm{M}$ Phx-3, for $24-72$ h. Percentages (\%) of various cell cycle stages including $\mathrm{G}_{1} / \mathrm{G}_{0}, \mathrm{~S}$, and $\mathrm{G}_{2} / \mathrm{M}$ are depicted in the figures. 
It has been recognized that drugs causing apoptosis in cancer cells exert less adverse effects, because apoptotic cells are engulfed by phagocytes whereas the membrane of necrotic cells is disrupted, and inflammation and release of toxic substances occur. Thus, the apoptogenic drugs may be beneficial for treating cancers. We showed that $\mathrm{Phx}-1$ or Phx-3-induced growth inhibition of MKN45 and KATO III, which are more malignant than MKN74 and MKN7, was associated with apoptosis/necrosis (Fig. 3), suggesting that these pheno-xazines may be beneficial agents to treat gastric cancer.

The activation of caspase family proteases, including caspase- 3 is considered to be involved in cellular apoptosis $(21,22)$. However, according to recent reports $(25-27)$, a caspase-independent pathway associated with apoptosis inducing factor (AIF) and Bcl-2/19 kDa interacting protein-3 (BNIP3) is operating in induction of apoptosis. Park et al (23) indicated that allicin, a major component of garlic, causes apoptosis in gastric carcinoma cells through caspaseindependent cell death pathway, accompanying the release of AIF from mitochondria instead of the activation of caspase- 3 . We demonstrated that caspase- 3 was not activated at $24 \mathrm{~h}$ in MKN45 treated with Phx-1 and in KATO III treated with Phx-1 and Phx-3 (Fig. 4), while it was much activated at $24 \mathrm{~h}$ in MKN45 treated with Phx-3 (Fig. 4A). These results suggest that activation of caspase- 3 was not involved in the apoptogenesis in MKN45 with Phx-1 and in KATO III with Phx-1 or Phx-3. Furthermore, with regard to MKN-45 treated with $\mathrm{Phx}-3$, apoptosis and growth inhibition of MKN45 caused by Phx-3 was not reversed to normal levels by z-VAD-fmk, a pan-caspase inhibitor (Fig. 5B and C), in spite of the cancellation of activation of caspase-3 (Fig. 5A). These results strongly suggest that induction of apoptosis in human gastric cancer cell lines, MKN45 and KATO III is not caused by the activation of caspase-3, but may be related with some caspase-independent pathways including AIF and BNIP3 (25-27).

The prevention of cancer cells by anticancer drugs is shown to be linked to the cell cycle arrest $(28,29)$. The results in Fig. 6A and B show that the progression of cell cycle was arrested at $\mathrm{G}_{0} / \mathrm{G}_{1}$ phase in MKN45 treated with Phx-1, and at $\mathrm{G}_{0} / \mathrm{G}_{1}$ and S-phase in the cells with Phx-3 (Fig. 6A). This result is consistent with the reports that $\mathrm{Phx}-1$ and $\mathrm{Phx}-3$ prevented the cell cycle progression at various phases, i.e., arrest at $\mathrm{G}_{0} / \mathrm{G}_{1}$ in human malignant melanoma G-361 cells with Phx-3 (16), and arrest at $S$ and $\mathrm{G}_{2} / \mathrm{M}$ in human epidermoid carcinoma cell line KB with Phx-1 (30) and human leukemia cell line HAL-01 with Phx-1(14).

With regard to human malignant melanoma (16) and pancreatic cancer cells lines (18), antiproliferative effects of $\mathrm{Phx}-3$ were stronger than those of $\mathrm{Phx}-1$, which agrees with the present results on human gastric cancer cell lines (Fig. 2). Such differences in action mode between Phx-1 and Phx-3 may be the variation in chemical structure between these phenoxazines, i.e., the presence or absence of the methyl group in the tricyclic chromophore (Fig. 1), though details of the mechanism are still obscure.

Gastric cancers are very common tumors in adults $(1,2)$, but are often refractory to anticancer drugs. Thus, it is urgent to develop drugs exerting anticancer effects but with low adverse reaction. Present results suggest that Phx-1 and Phx-3 hold promise as agents to treat gastric cancer in the future.

\section{Acknowledgements}

We thank Professor J. Patrick Barron (International Medical Communication Center of Tokyo Medical University) for his review of the English manuscript. Present research was supported in part by funds from and High-Tech Research Project for Private Universities, and a matching fund subsidy from the Ministry of Education, Culture, Sports and Technology, Japan (2003-2007).

\section{References}

1. Crew KD and Neugut AI: Epidemiology of gastric cancer. World J Gastroenterol 12: 354-362, 2006.

2. Smith MG, Hold GL, Tahara E and El-Omar EM: Cellular and molecular aspects of gastric cancer. World J Gastroenterol 12: 2979-2990, 2006

3. Osaki M, Tanabe S, Goto A, Hayashi H, Oshimura M and Ito H: 5-Fluorouracil (5-FU) induced apoptosis in gastric cancer cell lines: role of the p53 gene. Apoptosis 2: 221-226, 1997.

4. Vanhoefer U, Rougier P, Wilke H, Ducreux MP, Lacave AJ, van Cutsem E, Planker M, Santos JG, Piedbois P, Paillot B, Bodensein H, Schmoll HJ, Bleiberg H, Nordlinger B, Couvreur ML, Baron B and Wils JA: Final results of a randomized phase III trial of sequential high-dose methotrexate, fluorouracil and doxorubicin, versus etoposide, leucovorin and fluorouracil, versus infusional fluorouracil and cisplatin in advanced gastric cancer: a trial of the European Organization for Research and Treatment of Cancer Gastrointestinal Tract Cancer Cooperative Group. J Clin Oncol 18: 2648-2657, 2000.

5. Barry MA, Behnke CA and Eastman A: Activation of programmed cell death (apoptosis) by cisplatin, other anticancer drugs, toxins and hyperthermia. Biochem Pharmacol 40: 2353-2362, 1990.

6. Green DR and Reed JC: Mitochondria and apoptosis. Science 281: 1309-1312, 1998.

7. Thornberry NA and Lazebnik Y: Caspases: enemies within. Science 281: 1312-1316, 1998.

8. Brockman H, Bohnsack G and Franck B: Zur Konstitution der Actinomycine. Angew Chem 68: 70-71, 1956.

9. Hollstein U: Actinomycin. Chemistry and mechanism of action. Chem Rev 74: 625-652, 1974.

10. Motohashi N: Test for antitumor activities of phenothiazines and phenoxazines. Yakugaku Zasshi 103: 364-371, 1983.

11. Motohashi N, Mitshcer LA and Meyer R: Potential antitumor phenoxazines. Med Res Rev 11: 239-294, 1991.

12. Tomoda A, Arai S, Ishida R, Shimamoto T and Ohyashiki K: An improved method for the rapid preparation of a novel antitumor agent. Biorg Med Chem Lett 11: 1057-1058, 2002.

13. Shimizu S, Suzuki M, Tomoda A, Arai S, Taguchi H, Hanawa T and Kamiya S: Phenoxazine compounds produced by the reactions with bovine hemoglobin show antimicrobial activity against non-tuberculosis mycobacteria. Tohoku J Exp Med 203: 47-52, 2004.

14. Shimamoto T, Tomoda A, Ishida R and Ohyashiki K: Antitumor effects of novel phenoxazine derivative on human leukemia cell lines in vitro and in vivo. Clin Cancer Res 7: 704-708, 2001.

15. Abe A, Yamane $M$ and Tomoda A: Prevention of growth of human lung carcinoma cells and induction of apoptosis by a novel phenoxazine, 2 -amino-4,4 $\alpha$-dihydro- $4 \alpha, 7$-dimethyl-3Hphenoxazine-3-one. Anticancer Drugs 12: 377-381, 2001.

16. Shimizu S, Suzuki M, Miyazawa K, Yokoyama T, Ohyashiki K, Miyazaki K, Abe A and Tomoda A: Differentiation and apoptosis in human malignant melanoma G-361 cells induced by 2-aminophenoxazine-3-one. Oncol Rep 14: 41-46, 2005.

17. Koshibu-Koizumi J, Akazawa M, Iwamoto T, Takasaki M, Mizuno F, Kobayashi R, Abe A, Tomoda A, Hamatake M and Ishida R: Antitumor activity of a phenoxazine compound, 2amino-4,4 $\alpha$-dihydro-4 $\alpha$,7-dimethyl-3H-phenoxazine-3-one against human $\mathrm{B}$ cell and $\mathrm{T}$ cell lymphoblastoid cell lines: induction of mixed types of cell death, apoptosis, and necrosis. J Cancer Res Clin Oncol 128: 363-368, 2002. 
18. Kato S, Shirato K, Imaizumi K, Toyoda H, Mizuguchi J, Odawara M, Che XF, Akiyama S, Abe A and Tomoda A: Anticancer effects of phenoxazine derivatives combined with tumor necrosis factor-related apoptosis-inducing ligand (TRAIL) on pancreatic cancer cell lines, KLM-1 and MIA-PaCa-2. Oncol Rep 15: 843-848, 2006.

19. Mori H, Honda K, Ishida R, Nohira T and Tomoda A: Antitumor activity of 2 -amino-4, $4 \alpha$-dihydro- $4 \alpha, 7$-dimethyl-3Hphenoxazine-3-one against Meth A tumor transplanted into BALB/c mice. Anticancer Drugs 11: 653-657, 2000.

20. Kurosaki N, Kurosaki Kasuga T, Shirato K, Endo T and Tomoda A: 2-Aminophenoxazine-3-one suppresses the growth of mouse malignant melanoma B16 cells transplanted into C57/ B16Cr Slc mice. Biol Pharm Bull (In press).

21. Green D and Kroemer G: The central executioners of apoptosis: caspases or mitochondria? Trends Cell Biol 8: 267-271, 1998.

22. Hail BZ Jr, Carter M, Konopleva and Andreeff M: Apoptosis effector mechanisms: a requiem performed in different keys. Apoptosis 11: 889-904, 2006.

23. Park S-Y, Cho S-J, Kwon H-C, Lee K-R, Rhee D-K and Pyo S: Caspase-independent cell death by allicin in human epithelial carcinoma cells: involvement of PKA. Cancer Lett 224: 123-132, 2005.

24. Nagamine M, Okumura T, Tanno S, Sawamukai M, Motomura W, Takahashi $\mathrm{N}$ and Kohgo Y: PPAR $\gamma$ ligand-induced apoptosis through a p53-dependent mechanism in human gastric cancer cells. Cancer Sci 94: 338-343, 2003.
25. Lorenzo HK, Susin SA, Penninger J and Kroemer G: Apoptosis inducing factor (AIF): a phylogenetically old, capaseindependent effector of cell death. Cell Death Differ 6: 516-524, 1999.

26. Vande Velde C, Cizeu J, Dubik D, Alimonti J, Brown T, Israels S, Hakem R and Greenberg AH: BNIP3 and genetic control of necrosis-like cell death through the mitochondrial permeability transition pore. Mol Cell Biol 20: 5454-5468, 2000.

27. Hong SJ, Dawson TM and Dawson VL: Nuclear and mitochondrial conversation in cell death: PAPP-1 and AIF signaling. Trends Pharmacol Sci 25: 259-264, 2004.

28. Tobey RA: Different drugs arrest cells at a number of distinct stages in G2. Nature 254: 245-247, 1975.

29. Sen S and D'Incarci M: Apoptosis: biochemical events and relevance to cancer thermotherapy. Fed Eur Biochem Soc 307: 122-1227, 1992.

30. Ishida R, Yamanaka S, Kawai H, Ito H, Iwai M, Nishizawa M, Hamatake $\mathrm{M}$ and Tomoda $\mathrm{A}$ : Antitumor activity of 2-amino4,4 $\alpha$-dihydro-4 $\alpha, 7$-dimethyl-3H-phenoxazine-3-one, a novel phenoxazine derivative produced by the reaction of 2-amino-5methylphenol with bovine hemoglobin. Anticancer Drugs 7: 591-595, 1996. 